\title{
Torque and Electrical Activation of the Rectus Femoris Muscle at Distinct Joint Angles: A Case Study
}

\author{
Anelize CINI (D), Francesca SONDA (D), Isabel de Almeida PAZ (D, Ana Paula Janner \\ ZANARDI ID and Grazielle Martins GELAIN* iD
}

Department of Exercise Research Laboratory (LAPEX), Federal University of the State of Rio Grande do Sul, Brazil

*Corresponding author: Grazielle Gelain, Department of Exercise Research Laboratory (LAPEX) of the Federal University of the State of Rio Grande do Sul, Brazil

\begin{abstract}
The angulation of knee and hip joints affect isometric contractions of Rectus Femoris muscle (RF) during knee extension. Literature states that torque-angle relationship depends on muscle length and neuromuscular electrical activation. However, it is still not clear whether the maximum neuromuscular activation changes concomitantly with the change in the joint angles considering the presence of muscle shortening. We present a case study in which we analyzed changes in neuromuscular activation and peak torque of the RF at distinct joint angles of hip and knee.
\end{abstract}

\section{Keywords}

Electromyography, Quadriceps, Torque, Toque-angle relationship

\section{Introduction}

The search for evidence in the theories related to mechanisms of muscle contraction has led to the emergence of the torque-angle relationship [1]. Some studies report the influence of neural activation in this relationship. However, there is still no consensus among the authors whether neural activation remains constant regardless of the muscle length [2], or whether it increases [3-5] or decreases [6] with diminution of muscle length.

Some researchers have found that, during isometric contractions of RF at 70 of knee flexion, the ability to produce force also depends on the hip joint angle, which affects RF length too [7,8]. For instance, knee extension torque is greater at $80^{\circ}$ of hip flexion than it would be at $0^{\circ}[9]$. However, one study found greater torque and EMG activity of Maximal Voluntary Isometric Contraction (MVIC) close to $90^{\circ}$ of hip flexion [10] while another study also found the highest activations between $60^{\circ}$ and $80^{\circ}$, followed by $85^{\circ}$ and $90^{\circ}$ [6]. However, they did not correlate these results considering the muscle length of antagonistic musculature.

In addition, the change in hip and knee joint angles not only alters neural activation and length of the RF, but also of the hamstrings. For instance, when the hip joint angle is maintained at $80^{\circ}$ during MVIC performed in different angles of knee extension, hamstring co-activation is present in all angulations $[11,12]$.

Literature states that torque-angle relationship depends on both muscle length and neuromuscular electrical activation. However, it is still not clear whether the maximum neuromuscular activation changes concomitantly with the change in the joint angles. Thus, the aim of this study is to assess neuromuscular activation and peak torque of RF at distinct hip and knee joint angles.

\section{Case Report}

Our subject was a 23-years-old female, $73 \mathrm{~kg}, 1.57$ $\mathrm{m}$, body mass index of 30.43 , physically active, without known impairment of the musculoskeletal system affecting the spine or the lower extremities. She underwent flexibility assessment of hamstrings, soleus and gastrocnemius muscles of her right lower limb (dominant limb), which was followed by the assessment of extensor torque peak and neuromuscular electrical activation through surface electromyography.

Citation: CINI A, SONDA F, de Almeida PAZ I, ZANARDI APJ, GELAIN GM (2020) Torque and Electrical Activation of the Rectus Femoris Muscle at Distinct Joint Angles: A Case Study. Int J Sports Exerc Med 6:159. doi.org/10.23937/2469-5718/1510159

Accepted: February 19, 2020; Published: February 21, 2020

Copyright: (C) $2020 \mathrm{CINI} \mathrm{A}$, et al. This is an open-access article distributed under the terms of the Creative Commons Attribution License, which permits unrestricted use, distribution, and reproduction in any medium, provided the original author and source are credited. 
A universal plastic goniometer was used to evaluate ROM of joints. Knee extension was assessed in the supine position. The hip and knee were flexed at $90^{\circ}$ keeping the ankle relaxed. From this position, her knee was passively and slowly extended by examiner 1 , while examiner 2 ensured that no pelvic compensations occurred. The subject was oriented to communicate to the examiner the exact moment she felt tension in the hamstrings. That moment was considered the final position of the test, which resulted in $34^{\circ}$ of knee flexion, indicating decreased muscle length. Muscle shortening is present if the individual cannot fully extend the knee $\left(0^{\circ}\right)$ while maintaining the hip at $90^{\circ}$ of flexion $[13,14]$.

To evaluate ROM of ankle dorsiflexion, the subject was positioned sitting forward in a backless chair with knees bent and feet pulled back toward chair enough to raise the heels slightly from the floor. A pressure on the thighs forced the heels towards the ground. The test showed $20^{\circ}$ of ankle dorsiflexion (normal muscle length). Angles less than $20^{\circ}$ are indicative of shortening of soleus and gastrocnemius [15]. The subject remained seated for neuromuscular activation and force tests.

The assessment of neuromuscular activation was performed concurrently with maximal knee extension tests. Isometric contractions of extensors muscle of the right knee were performed on an isokinetic dynamometer (Biodex System 3, Biodex Medical System, USA). An electromyograph (Miotool 400, Miotec, Porto Alegre, Brazil), with $2 \mathrm{kHz}$ frequency and 8 channels, was used to assess the electrical activity of the RF. We followed the recommendations of SENIAM (Surface Electromyography for the Non-Invasive Assessment of Muscles).

Primary, keeping the hip joint angle at $90^{\circ}$ of flexion, the patient performed a warm-up protocol on the dynamometer, which consisted of 10 repetitions of knee flexion - extension at a speed of $90^{\circ} / \mathrm{s}^{-1}$ applying submaximal force. Subsequently, an isometric torque evaluation was performed in three different knee joint

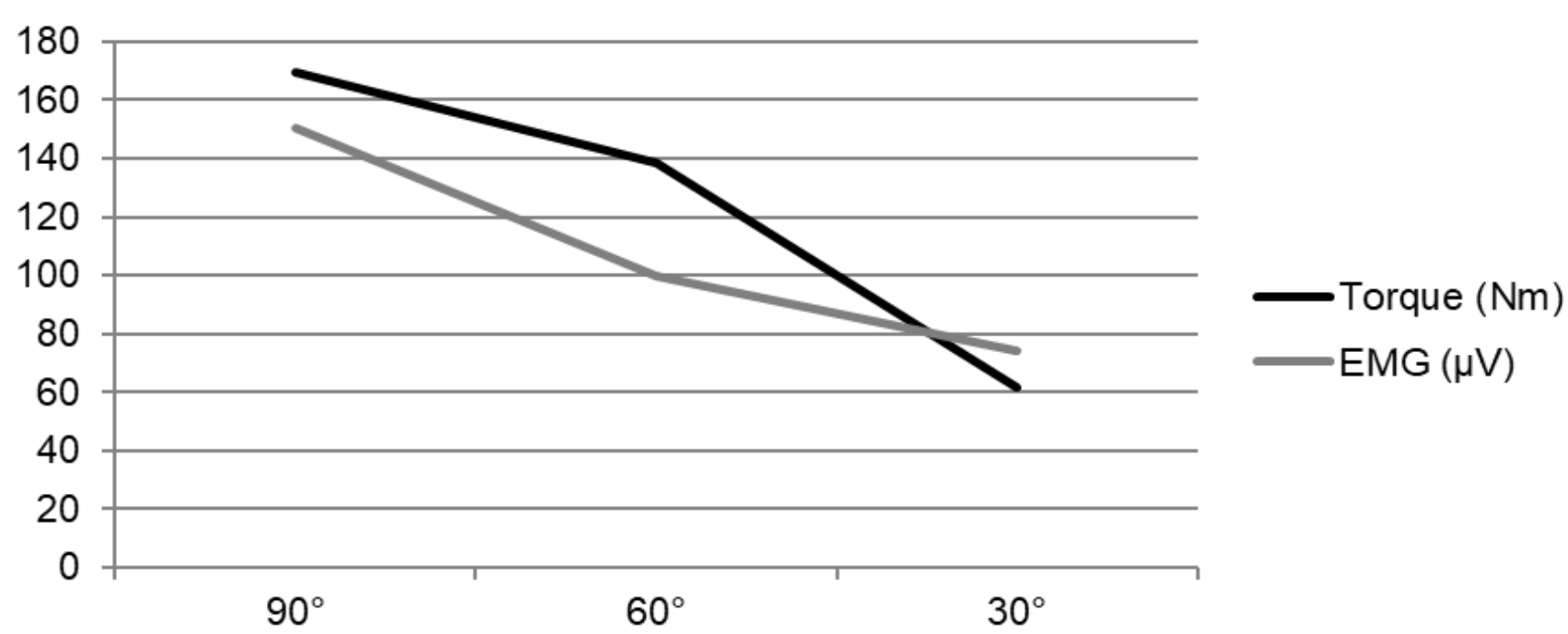

Figure 1: Assessment of isometric torque and neuromuscular activation of RF (hip joint angle at $90^{\circ}$ of flexion and variations at knee joint angles $\left(90^{\circ}, 60^{\circ}\right.$ and $\left.30^{\circ}\right)$.

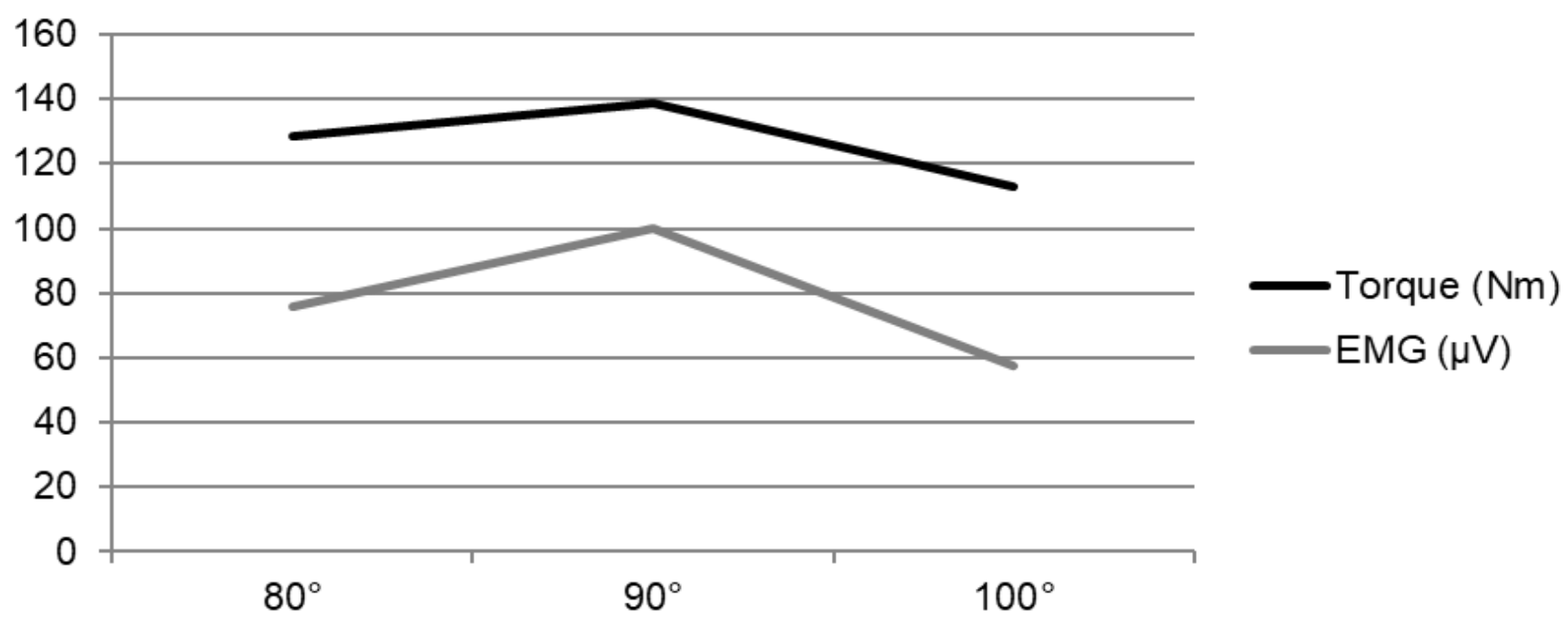

Figure 2: Assessment of isometric torque and neuromuscular activation of RF (knee joint angle at $90^{\circ}$ of flexion and variations at hip joint angles $\left(80^{\circ}, 90^{\circ}\right.$ and $\left.100^{\circ}\right)$. 
angles $\left(30^{\circ}, 60^{\circ}\right.$ and $\left.90^{\circ}\right), 0$ degree being full knee extension. Three 5 -seconds MVICs, with two-minute rest period in between, were performed at each knee joint angle. A second sequence of trials was performed keeping the knee at $60^{\circ}$ of flexion while hip joint angle was fixed at three different angles: $80^{\circ}$ (pelvic anteversion), $90^{\circ}$ (neutral pelvis) and $100^{\circ}$ (pelvic retroversion). Again, three 5 -seconds MVICs, with two-minute rest period in between, were performed at each knee joint angle.

Electromyographic signals were analyzed using $\mathrm{Mi}-$ otec Suite software (fifth-order Butterworth bandpass filter, cutoff frequencies between 20 and $500 \mathrm{~Hz}$ ). At $90^{\circ}$ of hip flexion, electromyographic signals and torque values showed the greatest torque and activation of the $\mathrm{RF}$ occurred with the knee at a $90^{\circ}$ of flexion (Figure 1 ).

When the knee was fixed at $60^{\circ}$, the greatest activation and torque production of the RF was observed at the $90^{\circ}$ of hip flexion (Figure 2).

\section{Discussion}

Several authors use angles between $60^{\circ}$ and $75^{\circ}$ of knee flexion to evaluate the maximal force production of knee extensors and flexors, but the hip angle for the best torque-angle relationship is $80^{\circ}$ [8,16-18]. However, for this subject, the optimal angle for neuromuscular activation of the RF and quadriceps torque was $90^{\circ}$ of flexion of hip and knee joint, corroborating with the findings of two other studies $[19,20]$.

Agonist (quadriceps) activation and antagonist (hamstring) co-activation differ in knee extension angles during MVIC and contribute to the torque-angle relationship. The neuromuscular activation of the quadriceps is decreased when it is more stretched [12].

Compared to the vast muscles, one study reported the RF was more active at $90^{\circ}$ and $120^{\circ}$ angles of knee extension in open kinetic chain than in closed chain exercises [21]. This may have influenced the result obtained in this case once the exercise performed by the subject was in open kinetic chain.

We speculate that at $100^{\circ}$ of hip flexion, the RF is activated in order to maintain body posture, what reduces the muscle capacity to produce torque in the extension of the knee. This finding may encourage the investigation of neuromuscular activation of hamstrings and other adjacent muscles considering antagonistic shortening.

\section{Conclusion}

The peak torque and the highest neuromuscular activation of RF occurred at $90^{\circ}$ of flexion of knee and hip joints. On the other hand, the lowest peak torque and neuromuscular activation occurred at $30^{\circ}$ of knee extension and $90^{\circ}$ of hip flexion. The muscle adaptation strategy varies for each individual and we speculate about the influence of the co-activation of the antagonistic musculature in the presence of muscular shortening.

\section{References}

1. Rassier DE, MacIntosh BR, Herzog W (1999) Length dependence of active force production in skeletal muscle. $J$ Appl Physiol 86: 1445-1457.

2. Gandevia SC, McKenzie DK (1988) Activation of human muscles at short muscle lengths during maximal static efforts. J Physiol (Lond) 407: 599-613.

3. Huber A, Suter E, Herzog W (1998) Inhibition of the quadriceps muscles in elite male volleyball players. J Sports Sci 16: 281-289.

4. Kasprisin JE, Grabiner MD (2000) Joint angle-dependence of elbow flexor activation levels during isometric and isokinetic maximum voluntary contractions. Clin Biomech (Bristol, Avon) 15: 743-749.

5. Linnamo V, Bottas R, Komi PV (2000) Force and EMG power spectrum during eccentric and concentric actions. J Electromyogr Kinesiol 10: 293-300.

6. Becker R, Awiszus F (2001) Physiological alterations of maximal voluntary quadriceps activation by changes of knee joint angle. Muscle Nerve 24: 667-672.

7. Babault N, Pousson M, Michaut A, Van Hoecke J (2003) Effect of quadriceps femoris muscle length on neural activation during isometric and concentric contractions. J Appl Physiol 94: 983-990.

8. Pincivero DM, Coelho AJ, Campy RM, Salfetnikov Y, Suter E (2003) Knee extensor torque and quadriceps femoris EMG during perceptually-guided isometric contractions. J Electromyogr Kinesiol 13: 159-167.

9. Ema R, Wakahara T, Kawakami Y (2017) Effect of hip joint angle on concentric knee extension torque. J Electromyogr Kinesiol 37: 141-146.

10. Lanza MB, Balshaw TG, Folland JP (2017) Do changes in neuromuscular activation contribute to the knee extensor angle-torque relationship? Exp Physiol 102: 962-973.

11. Kubo K, Tsunoda N, Kanehisa H, Fukunaga T (2004) Activation of agonist and antagonist muscles at different joint angles during maximal isometric efforts. Eur J Appl Physiol 91: 349-352.

12. Aagaard P, Simonsen EB, Andersen JL, Magnusson SP, Bojsen-Møller F, et al. (2000) Antagonist muscle coactivation during isokinetic knee extension. Scand J Med Sci Sports 10: 58-67.

13. Feland JB, Myrer JW, Schulthies SS, Fellingham GW, Measom GW (2001) The effect of duration of stretching of the hamstring muscle group for increasing range of motion in people aged 65 years or older. Phys Ther 81: 1110-1117.

14. Polachini LO, Fusazaki L, Tamaso L (2005) Estudo comparativo entre três métodos de avaliação do encurtamento de musculatura posterior de coxa. Braz J Phys Ther 9: 187-193.

15. Kendall FP, McCreary EK, Provenance PG, Rodgers MM, Romani WA (2005) Muscles: Testing and Function with Posture and Pain. ( $5^{\text {th }}$ edn), Philadelphia (PA): Lippincott Williams \& Wilkins.

16. Baroni BM, Geremia JM, Rodrigues R, Borges MK, Jinha A, et al. (2013) Functional and morphological adaptations to aging in knee extensor muscles of physically active men. $J$ Appl Biomech 29: 535-542.

17. Rabita G, Pérot C, Lensel-Corbeil G (2000) Differential effect of knee extension isometric training on the different muscles of the quadriceps femoris in humans. Eur $\mathrm{J} \mathrm{Appl}$ Physiol 83: 531-538. 
18. Qi Z (2007) Influence of Knee Joint Position on Co-contractions of Agonist and Antagonist Muscles during Maximal Voluntary Isometric Contractions: Electromyography and Cybex Measurement. J Phys Ther Sci 19: 125-130.

19. Correa CS, Silva BGC da, Alberton CL, Wilhelm EN, Moraes $A C$ de, et al. (2011) Analysis of maximal isometric force and EMG signal in lower limb exercise. Revista Brasileira de Cineantropometria \&amp; Desempenho Humano 13: $429-435$.
20. Thompson BJ, Whitson M, Sobolewski EJ, Stock MS (2018) The Influence of Age, Joint Angle, and Muscle Group on Strength Production Characteristics at the Knee Joint. J Gerontol A Biol Sci Med Sci 73: 603-607.

21. Escamilla RF, Fleisig GS, Zheng N, Barrentine SW, Wilk $\mathrm{KE}$, et al. (1998) Biomechanics of the knee during closed kinetic chain and open kinetic chain exercises. Med Sci Sports Exerc 30: 556-569. 